\title{
E-Learning Islamic Studies for Form Four Students
}

\author{
Nazirah binti Mat Sin, Azira Ab Aziz, Hasmiza Othman, Seyed Ahmad Rahimi and Peter Woods \\ Faculty of Creative Multimedia, Multimedia University, Cyberjaya, Selangor 63100, Malaysia
}

Received: February 08, 2011 / Accepted: March 30, 2011 / Published: June 25, 2011.

\begin{abstract}
Despite the efforts by Ministry of Education to promote Information and Communication Technology (ICT) in education in Malaysia, the Islamic education syllabus is far behind the intended plan in ICT usage in learning and teaching. Concern was raised that Islamic Studies faced the risk of being misunderstood if the lessons were taught through self-accessing method with minimal intervention from teachers. Using the Dick and Carey instructional model as a framework, an e-learning version was devised for the national Form 4 Islamic Studies syllabus, “The steps and procedures of Hajj and Umrah”. The Islamic Studies textbook for national secondary schools in Malaysia was reviewed using a systematic approach, from identifying the instructional goal through to formative and summative evaluation processes. Interview sessions with students were conducted to assess the developed e-learning Islamic Studies content. A subsequent survey with students was conducted. Results from the study indicated the e-learning Islamic Studies content had the potential to help students, being easy to use, and attracting and retaining students' attention.
\end{abstract}

Key words: E-learning, islamic studies, dick and carey model.

\section{Introduction}

Despite the efforts by Ministry of Education to promote Information and Communication Technology (ICT) in education in Malaysia, the Islamic education syllabus is far behind the intended plan in ICT usage in learning and teaching. Problems have been identified including teachers and students' attitudes toward ICT in education, the facilities and resources, as well as the syllabus itself [1].

The concerns raised by the teachers in adopting ICT technology in the classroom surround the issues of making use of ICT as part of the pedagogy given to the nature of the syllabus itself. The consensus is that Islamic Studies is different from other subjects as it is not open to experimentation, thus no input-output formula can be tested [1].

It was also reported that the subject needed a creative and attractive teaching approach in class, that can engage the students' interest in the subject. Students were more attracted to use computer

Corresponding author: Nazirah binti Mat Sin, lecturer, research fields: multimedia, instructional technology, knowledge management. E-mail: nazirah.sin@mmu.edu.my. because it was more informative and had lots of pictures; in contrast to the normal teaching style which was monotonous and static [1]. However, by converting teaching materials in slides and projecting them onto the classroom wall does not signify e-learning because it does not help the learner extract the learning [2].

Initial work in producing a textbook compact disc (CD) courseware for English and Mathematics took place in 2003, commissioned by the Malaysian Ministry of Education. Further work in 2004-2005, resulted in CD courseware textbooks for Bahasa Malaysia (the national language) and English.

There was limited work being carried out for other non-core subjects, including Islamic Studies. The nature of the subject itself and the concept of self-accessing learning were believed unsuitable for a subject like Islamic Studies. It is regarded as a subject that is non-experimental, and cannot be tested and analyzed. This has been the stated reason for the non-development of e-learning content.

Islamic Studies has broad sub-topics that could be considered suitable for e-learning. This research is 
intended to source the tool to bridge the gap between the Islamic Studies subject and e-learning and subsequently serve as a guideline for future development of e-learning instruction for Islamic Studies.

The research scope is the Islamic Studies syllabus for Form Four pupils (16 years of age). The topic is Unit 2-Rukun Haji dan Umrah (The steps and procedures of Hajj and Umrah). The syllabus is for the fully government-funded national secondary schools in Malaysia. The study was designed to consider the potential strengths and weaknesses of e-learning content for Islamic Studies of Unit 2-Rukun Haji dan Umrah.

The paper is organized as follows: Section 2 discusses the content development. Section 3 describes research method used in the study. Section 4 presents results. Discussions of results are discussed in section 5. Lastly, section 6 provides conclusions followed by the study limitations in section 7.

\section{The Content Development}

The e-learning Islamic Studies had been developed based on Dick and Carey Systematic Instructional Design Model (D\&C Model). The D\&C Model consists of interlinked instructional disciplines that help the instructional designer to learn, understand, analyze and improve the practice of these disciplines. The term disciplines had been defined as “... theories and technique that must be studied and mastered and put into practice" [3]. As shown in Fig. 1, there are ten interconnected disciplines that represent the theories, procedures and techniques engaged by the instructional designer to design, develop and evaluate instructions, and finally revise them.

One of the advantages of D\&C Model is that it works well as a blueprint for instructional design regardless of the form of the intended instruction [4]. The intended delivery format of the Islamic Studies subject in this study is e-learning; a computer-based delivery format and the topic Unit 2-The steps and procedures of Hajj and Umrah is a procedural topic that includes steps and procedural learning objects.

The model is advantageous in the sense that it focuses on what learners are to know or be able to do at the end of the lesson, which without this, the succeeding planning and implementation can be confusing and unsystematic.

From the Dick and Carey's theoretical perspective-it is based on the understanding of the connection between the stimulus (instructional materials) and the reaction it produces in a learner. The theory talks about the process of identifying the sub-skills of the learners that they must have, and the intended outcome (behavior) that must be learned [4]. The theory focuses on the choice of the stimulus and

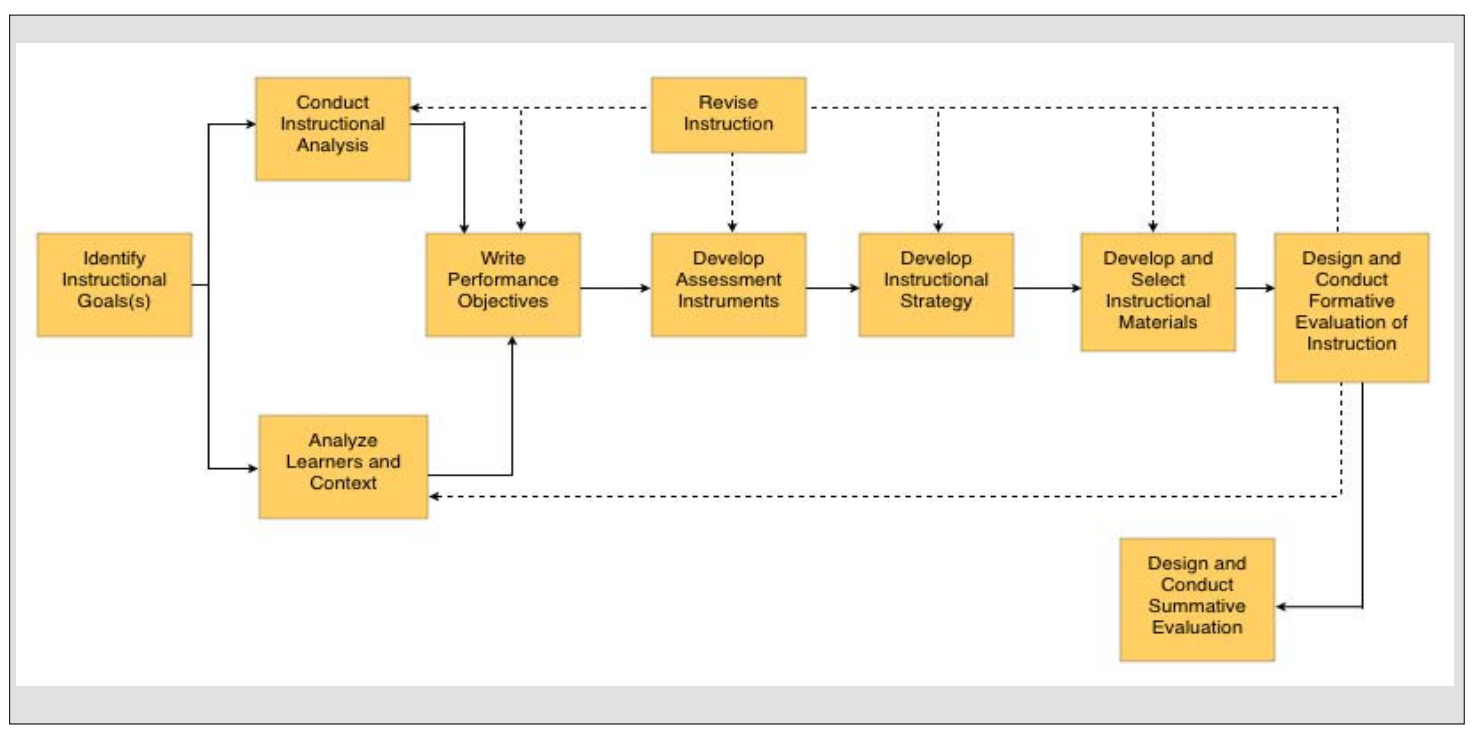

Fig. 1 Dick and Carey instructional system design (source from Dick and Carey model 2005). 
strategy for each sub-skill's development. The theory also recommends a procedural methodology of instructional development based on a reductionist model of “...breaking instruction down into smaller components” [4].

The learning will be demonstrated in the form of the ability of the learners to master a set of predictable behavior identified in earlier stage, which in this case, are the concepts, steps and procedures of performing the hajj and umrah [4].

The application (Fig. 2) had been developed using Adobe Flash Professional $\mathrm{CS}^{\odot}{ }^{\odot}$ and iLife08 Garageband $^{\odot}$ for Mac. Content was taken from the standard school syllabus textbook in order to ensure content validity and reliability. Next, the contents were structured based on Dick and Carey model. The content was converted into visual form and the scripts were prepared. The last stage was audio recording production for the e-learning content.

The choice of language of the instructions in the textbook was Jawi written in Arabic characters. In the e-learning instruction content, the text used Bahasa Malaysia with standard Roman characters.

Students could navigate the instructions in several ways. At the bottom of every screen page, students could navigate the instruction by clicking on the Back/Next button. They could also click on the topic list in the left pane. The instructions were designed in such a way to give a good quality of interface to the users.

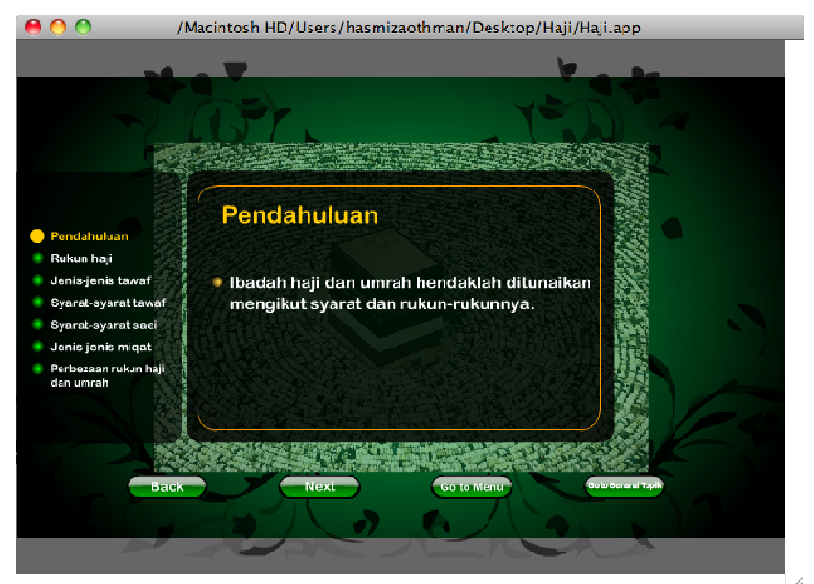

Fig. 2 Sample of e-learning screen.
The instructions were also developed in dual languages. The instruction content was maintained in Malay language (national language of Malaysia); this to provide students with similar context as the textbook students used was in Malay language. However the navigation menu, button captions, and other operational instructions were presented in English as most students were familiar of using navigation menu in English The instructions were also furnished with images of people in ihram, a picture of Kaabah and animated transitions to enhance students' understanding toward the topic.

\section{Research Method}

\subsection{Research Approach}

This study adopted both qualitative and quantitative approach. A qualitative method had been used in the first stage of the study. Participants first experienced the Islamic Studies course in an e-learning mode. Interview sessions were then conducted in order to gain insight into their assessment of the strength and weaknesses of the e-learning content. In the second stage of the study, a quantitative method had been used. A survey was conducted to identify the strengths and weaknesses of the e-learning Islamic Studies.

\subsection{Sample Group}

Purposive sampling was used in the study. In purposeful sampling, researchers intentionally select individuals and sites to learn or understand the central phenomenon [5].

In this study, participants selected were form four students in a government public secondary school (Sekolah Menengah Kebangsaan Desa Tun Hussein Onn). These participants had prior knowledge of Islamic Studies in Rukun Haji dan Umrah syllabus. As the developed e-learning content only covered this syllabus topic, it was crucial to select participants who had prior knowledge of the content. Eight students participated in the first stage of the study and 30 
students in the second stage. All the evaluation steps and procedures were adopted based on Dick and Carey textbook.

\subsection{Stage 1}

During this stage, data were collected through interviews. The main objective of this stage was to explore the strengths and weaknesses of the developed e-learning content.

Interview questions given to the participants were based on instruction criteria (Table 1). There were three specific categories considered in the interview sessions: message, links and procedures (Table 1). In the message category, questions seek the clarity of basic instruction in the e-learning to learners. In the link category, questions seek the achievement of content in meeting learners' learning need. In the procedure category, questions asked the participants whether the content was presented in appropriate sequence, transition and pace.

\subsection{Stage 2}

In the second stage of the study, a field test was conducted to further investigate the strengths and weaknesses of the e-learning instruction. During the session, a set of questions on learner's perceptions toward the e-learning Islamic Studies was given.

The session was assisted by the school Islamic Studies teacher, one technician and one supervising teacher. There were sixteen desktop computers available for the test; each accommodated two students and one reserved computer for the teacher in charge. During the session, the teacher demonstrated instructions of the e-learning courseware through the

Table 1 Evaluation criteria and the type of information for each element.

\begin{tabular}{|l|l|l|l|}
\hline & \multicolumn{3}{|c|}{ Aspects } \\
\cline { 2 - 4 } & Message & Links & Procedures \\
\hline Criteria & Introductions & & \\
Is the message, or & Vocabulary level & & Sequence \\
what is being & Sentence & Contexts & Sequnsition \\
presented, clear & complexity & Illustrations & Traniation \\
to individual & Message & & Variation \\
target? & complexity & & \\
\hline
\end{tabular}

projected image on the white screen. The session was conducted in a synchronous manner due to the fact that only the computer reserved for the teacher had loud speakers. The questionnaires were given to students at the end of the session.

\section{Results}

\subsection{Stage 1}

As mentioned in section 3 of this paper, three specific aspects had been addressed in the interview sessions; message, links and procedures. Results of stage 1 are reported following evaluation criteria as presented in Table 1.

\subsubsection{Message: Introduction}

When asked about the clarity of the introduction in the instructions, all participants responded the instruction was unambiguous and not confusing. For example one student said

"The introduction, it was ok. Clear."

Another student mentioned that

"No. Just ok, not confusing."

\subsubsection{Message: Vocabulary}

According to the feedbacks obtained from interview sessions, all participants agreed that vocabulary level used in the e-learning Islamic studies was appropriate. For example one student said

"Ok."

Another student said the e-learning Islamic study was "Suitable. Not difficult to understand."

\subsubsection{Message: Sentence Complexity}

In this session, participant were interviewed by the researcher to gain insights of the usage of Roman characters in substitute to Jawi writing. Besides that, participants were asked the ease to read and understand the writing of the e-learning Islamic study subject. Based on the findings gained interview sessions, all participants agreed that the sentence complexity was suitable. For example one participant said

"It's ok. Seems no different to me. Like the sentences in the text book. No problem.”

Another participant responded 
"I think because I always read book with Roman characters. The only book in Jawi is this subject. Of course it's the Roman character."

Another participant informed the reason he felt the sentence complexity was suitable because the language used in the e-learning was consistent with the language used in text book. The participant responded

"No [it does not contort the meaning]. Both are Malays."

\subsubsection{Message: Message Complexity}

At the beginning of the instruction, students were provided with simple narration on the usage of the e-learning Islamic study. An extensive audio narration was used during the instructions. Findings gained from interview sessions indicated that 7 out of 8 participants felt that the background narration was clear, relevant and ultimately helpful in conveying the lesson. For example, one of the participants said

"Easy to understand. Not fast. Sounds like an ustaz [Islamic teacher] teaching. When we hear it, we don't feel bored because it doesn't sound like someone reading."

However, one participant provided a contrary feedback. According to the participant

"But, what he says is different from what we can see on the screen! Well...you see, we can see there are only a few words on the screen, but when he explains, it becomes lengthy. ...no Sir. I think it is not good. Because almost all computers here do not have speakers. We cannot learn if we want to use the application here. We can only learn if the speakers are there. It's going to be difficult.”

\subsubsection{Link: Contexts}

All eight participants agreed that the link should be in English caption. When asked, they affirmed that it was the standard that they were familiar with. They explained that the familiarization with English operational instructions came from the experience in using Internet, web browsing or games. When asked if they wanted it to be presented in Bahasa Malaysia, all of them agreed that it would be sound funny, awkward and not necessary. One of the participants remarked

"Ok because all computers are in English. If we read blogs or MySpace, they are all in English. We are used to it. We write in Malay but all the instructions are in English. Games are also like that, they are all in English. No need to change! It will sound weird!”

Another participant made a parallel remark

"I don't know. But it will be difficult to translate, you want go back and the word is 'undur'. Funny isn't it?! We are so use to 'back' and 'next'. It's ok. No need to change anymore."

\subsubsection{Link: Illustration}

The color scheme used in the instructions is turquoise blue as the background and grey as the text background with white as the text color. Other aspects of schemes like the font type and size are also tested for appropriateness. When asked if the color scheme, the font type and size distracted their attention during the lesson, seven students remarked that it did not distract their attention. However, 1 student commented, the color was unattractive, the font size was large and out of proportion. The participant commented

"Beautiful. I like it. The color is okay. A little bit dark, though. I like it. It's like reading an adult book! I don't know. But the color looks...how can I say this? It's the color for old people! I have seen my father use Maybank2U. It's the same. The font size is too big.”

Although one participant had perceived illustration in the e-learning Islamic study was inappropriate, majority of the participants did not find it critical. It can be concluded that the negative remarks given by one of the participants was just a personal preference.

\subsubsection{Procedures: Sequence}

In order to give the instructions the closest resemblance to the textbook, the instructions' content are arranged in similar sequences found in the textbook. The e-learning instructions begin with an introductory page followed by the topics list page and the lessons menu which at the same time provides links to the lesson objectives and conclusion. When asked about sequence of the e-learning Islamic studies, all eight 
participants agreed that the sequences were simple, in logical manner and suggested the same approach should be applied for future development. One of the participants remarked

"It's ok. Easy to follow. It's like a book. It would be really good if all applications are like this. It's easy to use. You don't get lost. If you sell this, you will make a good fortune!”

\subsubsection{Procedures: Transition}

Transitions and links are used on screens and objects to give an engaging effect to the instructions. They are intended to minimize complexity in the instruction by providing blinking arrow to show the button to click on or hyperlinks for shortcuts. The instructions also have buttons and menu list to provide more than one ways to open the intended page during the lesson. At the bottom of every screen, students can navigate the instruction by clicking either on the Back/Next button or the topic list in the left pane (Fig. 3).

When asked during interview sessions, participants commented that they if the transition affect, which according to them was 'beautiful', 'impressive', and of high quality design. One of the participant remarked

"Beautiful! I like it."

Another participant gave similar feedback

"Me too. How did you do it, sir? It looks 'expensive' and 'impressive', just like the ones from Internet."

Although most participants (7 out of 8) agreed with the transition provided in e-learning, one participant gave contrary feedback. According to the participant,

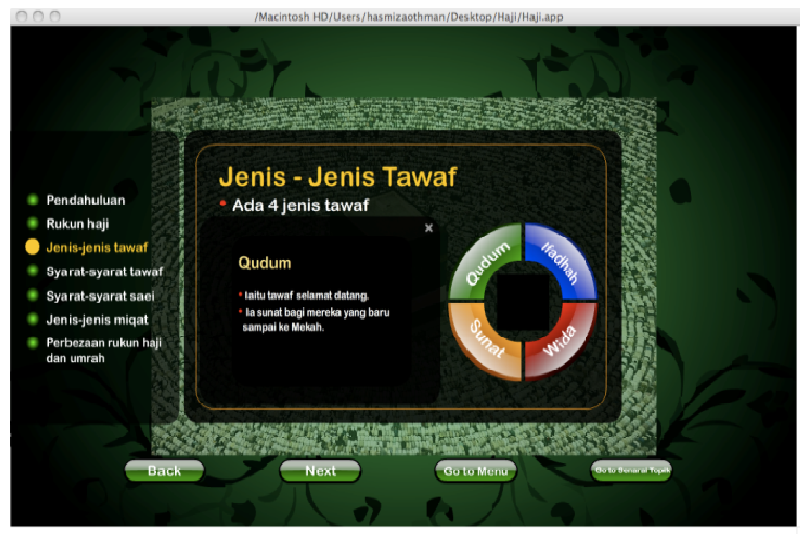

Fig. 3 Transition and links of e-learning Islamic Studies.
"For me, it’s just...OK. Nothing impressive. I think it should be the same until the end. By that, it will give the impression like flipping a page from the book. You know, page by page, from cover to cover."

\subsubsection{Procedures: Variation}

The e-learning instructions are furnished with elements like pictures, videos, audio and animated transitions to provide the instructions with maximum learning quality. A picture of Kaabah is used in the introductory page followed by pictures of people in ihram attire. During the interview sessions, students highlighted that the pictures used were appropriate and attractive. They explained that those pictures gave the realm of the lesson in the instructions. They could visualize the lesson clearly with the presence of pictures in the instructions. For better impact, they suggested for more pictures to be included. As for the videos, three short video clips were included as a supplementary visual aid in the instructions. Students agreed that three video clips were adequate to function as additional source of information.

One of the participants remarked

"I like the pictures because they show the people in Mekah. There are pictures of Kaabah, people in ihram. I feel like I'm part of the scene. I can relate with the lesson better."

Another participant provided similar comment:

"I agree. The videos, they are good, too! Three videos are sufficient. We know how Mekah is, so they are [videos] the same."

However one participant commented that the elements had no major impact in comprehension of the lesson. The participant commented

“The pictures are 'just ok'. I think I still can learn without those pictures because this topic is easy. I can understand the lesson only by reading [without the help of pictures].”

\subsection{Stage 2}

This stage reports participants' responses toward the e-learning Islamic studies. Responses received from 
questionnaires were inference and reported based on the seven constructs (Fig. 4) [1-3].

4.2.1 Construct 1-Deliver the Content with the Help of Multimedia

E-learning content consisting of videos, graphics, text and audio can be recorded, stored and broadcasted and shared among the students for personal and group use. $60 \%$ of the students responded that e-learning delivered the content effectively with the presence of multimedia elements in it (Fig. 5).

4.2.2 Construct 2-Provide Easy-to-Use Feature to the Users

All students responded that the interactive instructions like what they had just tested was easy to use (Response percentile $=100 \%)$ and simple (Response percentile $=$ 40\%). They said that learning with interactive instructions like this one gave them more control over the lesson (Response percentile $=70 \%$ ); that they could use this application at home and learned individually. Students also said it was easy to understand the topic (Response percentile $=40 \%$ ) (Fig. 5).

4.2.3 Construct 3-Make the Learning Less Dependent on Teachers

3 students responded they do not need teachers to be present (Response percentile $=10 \%$ ) (Fig. 5).

4.2.4 Construct 4-Simplify the Learning Process

Students added that the background narration in the instructions was the teacher itself and that would be sufficient to simplify the learning thus making lesson easy to remember (Response percentile $=10 \%$ ) (Fig. 5).

4.2.5 Construct 5-Make Learning Fun because It Has Lots of Pictures and Colors

Students reported that learning with application like e-learning is fun because of the presence of pictures and colors (Response percentile $=20 \%$ ). It also attracts their attention to stay focus in the lesson until the end (Response percentile $=90 \%$ ) (Fig. 5) .

4.2.6 Construct 6-Act as Aid to Teachers and Learners in Learning

The e-learning instructions were intended for individual self-learning. The combination of different

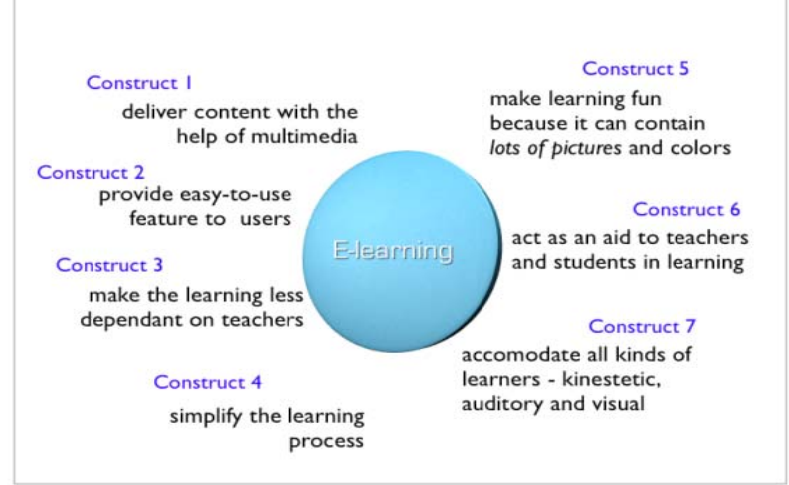

Fig. 4 The seven constructs of e-learning.

elements of media in e-learning makes the application interesting and attractive. Students highlighted that they would like to see more subject in e-learning (Response percentile $=50 \%$ ). Students also reported that they did not need the textbook (Response percentile $=20 \%$ ) when they used the application because the application provided ample information about the lesson (Fig. 5).

As shown in Fig. 5, five elements that received 50\% and above responses were recorded 'above average' and acknowledged as the strength, they are multimedia help learning, ease of use, more control, attract attention and e-learning is good for other subject. While, another six elements were considered the weaknesses: Simple, easy to understand, no teachers, needed, easy to remember, fun and no textbook needed.

\section{Discussion}

\subsection{Stage 1}

From this study, it is clear that the Islamic Studies e-learning had an essential role in promoting learning. The knowledge acquisition by students that takes place during the session may be conveyed by a number of different media. An effective learning experience can occur when the media work coherently in delivering the lesson [6]. A part of knowledge is acquired by students from viewing the videos, whereas in other part of learning it takes place by reading the text, listening to the audio and viewing the graphics. A combination of several media formats together is often necessary in 


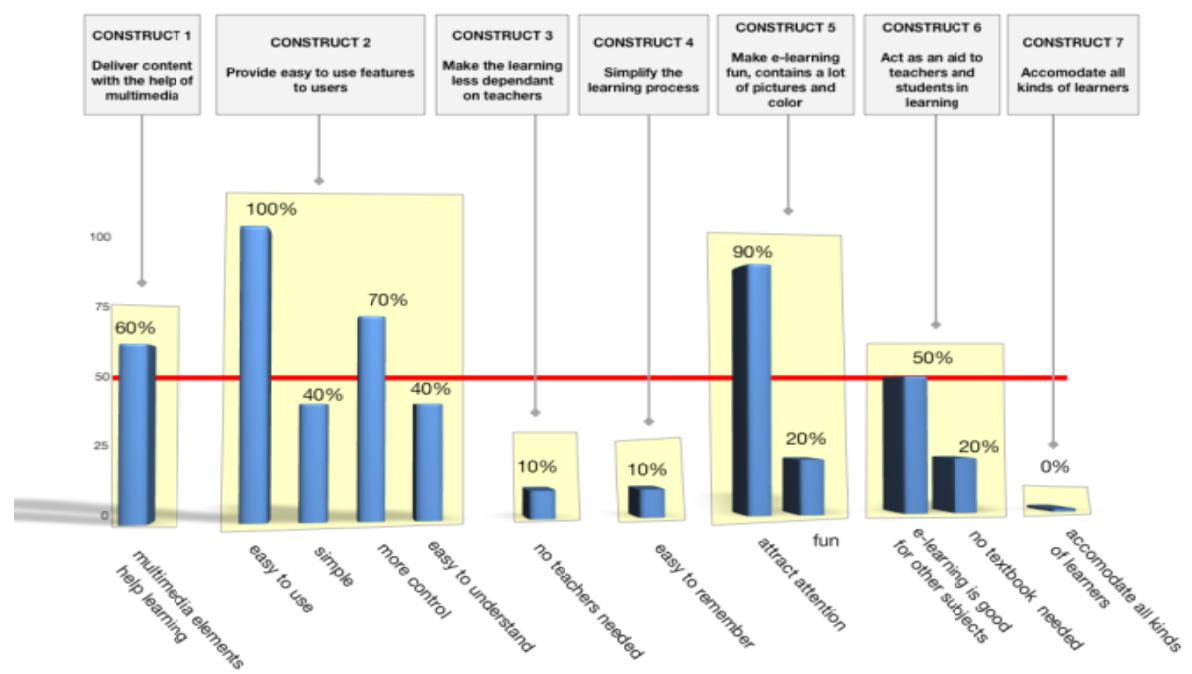

Fig. 5 Respondents' responses based on the seven construct of e-learning.

order for instructional materials to be effective. Here, the quality of the multimedia elements included in the instructions is acceptably good and hence they have the capability to promote learning.

\subsection{Stage 2}

A well created e-learning content could increase students' attention and interest toward the subject. Besides that, integration of appropriate multimedia in e-learning content could stimulate learners' engagement and thus ensure the success of e-learning instruction [7]. Based on the literature review, result in construct 1 (Fig. 5) shows $60 \%$ respondents felt that the developed multimedia content of e-learning Islamic Studies was useful in their learning: This indicated the strength of the e-learning Islamic Studies. Besides that, it could be assumed the e-learning product had the potential to stimulate students' engagement toward the subject.

Data retrieved from construct 2 (provide easy to use features to users) shows that all respondents felt the e-learning content was easy. This indicated the e-learning Islamic Studies is user-friendly. User-friendliness aspect is important in increasing students' motivations to learn the subject. A user-friendly criterion is also important in ensuring any e-learning course success. Findings in construct 2 also indicate most users of the e-learning Islamic
Studies had more control over the lesson. This finding parallel with literature review; user-control in e-learning instruction is important to maintain students' motivation toward the e-learning subject [8]. Although the e-learning Islamic Studies received well responses in user-friendliness and user-control categories, the level of simplicity and easy to understand categories received below average responses. Simplicity had been defined as uncomplicated, simple and straightforward. Thus, this indicated that the weaknesses of e-learning Islamic studies as complicated. In category of "easy to understand", respondents rated the e-learning Islamic Studies as "harder" to understand the content. This finding indicated the weakness of the e-learning Islamic studies; understandable key point of the e-learning Islamic studies is very low.

In construct 3 category (make the learning less dependent on teachers) shows only less number of respondents felt teacher's presence was not required. This indicated majority of the respondents felt that teacher's presence during e-learning session is crucial. When further asked, respondents informed that teacher's presence was necessitated in assisting learners to clarify any confusion during learning. Findings from the study were parallel with literature review; teacher's presence affected students learning, cognition and motivation [9]. 
Data retrieved from construct 4 (Simplify the learning process) indicated that respondents felt the e-learning lesson was difficult to remember. Only few students thought the subject was easy to remember. The e-learning instructions were intended for individual self-learning. The ideal set up for e-learning instructions was one student for one desktop; equipped with all the necessary peripherals such as the loud speakers. However it can be assumed that responses received for construct 4 was below average due to the setting of the session. There were sixteen desktop computers available for the test; each accommodated two students and one reserved for the teacher. The session was led by an Islamic Studies teacher who demonstrated the instructions through the projected image on the white screen. The session was conducted in a synchronous manner due to the fact that only the computer reserved for the teacher had the loud speakers. The distractions happened when the students had to keep looking at the projector's screen to keep abreast with the narration. That limitation gave a negative impact on the "easy to remember" element in this project. Alternatively, had the loud speakers attached to their computer, the result would have been otherwise.

In construct 5 (Make e-learning fun, contain a lot of pictures and colors) category, majority of the respondents felt the e-learning lesson did attract their attentions. Findings from this category indicated, respondents agreed the e-learning lesson provided users with appropriate visual clarity, high and readable color contrast and well-organized content.

These well received responses showed that respondents felt motivated and interested toward the e-learning lesson. However, less number of respondents felt that the e-learning lesson was fun. It can be assumed that participants were from high computer-literacy background might compare the e-learning lesson with other online games or other online entertainment content. Findings from this category provided with crucial information that the "fun" factor is important when developing e-learning subject.
In construct 6 category (Act as an aid to teachers and students in learning), half of the respondents felt that e-learning lesson should be introduced to other subjects. This indicated, younger generations are more than ready to hybrid learning mode; A combination of face-to-face study and e-learning mode. However, less number of respondents felt textbook usage in school is still important and the usage should be maintained.

\section{Conclusions}

As a conclusion, it had been identified that the e-learning Islamic studies had the potential to stimulate students' engagement and motivation towards learning Islamic Studies subject by providing users with appropriate multimedia usage, user-friendliness instructions, empowered users of more control toward the content and provide elements that could attract learners' attention. These potentials were seen also as strengths of the e-learning Islamic studies. Beside the strengths, many weaknesses had been identified throughout the study. One of the weaknesses is users having difficulty to remember the content as the 'fun' elements included in the e-learning Islamic Studies were very minimal.

As the study conducted was at the very early of stage, further studies are recommended to further investigate e-learning Islamic Studies potential. It is recommended for other researchers to conduct similar study with bigger sample size and to expand the scope of Islamic Studies syllabus covered in the study. Future researchers are also recommended to conduct similar study using different research design strategies such as experimental research or case study approach.

\section{Limitations}

\subsection{Sampling Size}

As the study conducted was at the very initial stage, a small sample size was used in the study. Thus, findings of the study could not be generalized and conclusions can only be applied in the study only. 


\subsection{Research Design}

Interview sessions and survey based questionnaire had been used to collect data in the study. Validity and reliability test were not conducted. However, the research procedures used Dick and Carey model as a basis of the study. Due to these limitations, findings of the study could only be seen as potential research study in the area of e-learning and Islamic Studies in schools.

\section{References}

[1] I. Hamzah, A. Ismail, M.A. Embi. The impact of technology change in Malaysian smart schools on Islamic education teachers and students, World Academy of Science, Engineering and Technology 49 (2009) 379-391.

[2] E. Blass, A. Davis, Buiding on solid foundations: establishing criteria for e-learning development, Journal of Further and Higher Education 27 (2003) 227-245.
[3] P. Senge, The Fifth Discipline: the Art and Practice of the Learning Organization, Currency Doubleday, New York, 1990.

[4] D. Walter, L. Carey, J.O. Carey, The Systemaic Design of Instruction, 6th ed., Allyn and Bacon, Boston, 2005.

[5] J.W. Creswell, Research Design, 3rd ed., Upper Saddle Creek, Pearson Education, NJ, 2008.

[6] T. Newby, D. Stepich, J. Lehman, J. Russell, Educational Technology for Teaching and Learning, Upper Saddle River, Merrill/Prentice Hall, NJ, 2006.

[7] S.E. Metros, J.G. Hedberg, More than just a pretty (inter) face: the role of the graphical user interface in engaging learners, Quarterly Review of Distance Education 3 (2002) 191-205.

[8] K.L. Smart, J.J. Cappe, Students' perceptions of online learning: a comparative study, Journal of Information Technology Education 5 (2006) 201-219.

[9] C. Baker, The impact of instructor immediacy and presence for online student affective learning, cognition, and motivation, Journal of Educators Online 7 (2010) 1-30. 